\title{
PRESENCIA Y ECOS DE FÁBULAS ESÓPICAS EN EL BALDO
}

TOMASA PASTRANA SANTAMARTA

Universidad de León ${ }^{1}$

\begin{abstract}
Resumen
El autor del Baldo nos presenta un libro de caballerías en el que la intención de entretenimiento no es menor que la de mostrar erudición y modelos de conducta apropiados en la sociedad, para ello introduce, al lado de las aventuras propias de estos libros, referencias a autores clásicos entre los que figura Esopo con alguna de sus fábulas recogidas en el Esopete ystoriado. En este estudio se ofrece una comparación de las fábulas esópicas que aparecen en ambos libros, se analizan sus variantes, distintas interpretaciones, así como el uso que el autor hace de las mismas en la obra: argumentar, dar consejos sobre modelos de conducta y mostrar las semejanzas en los comportamientos de hombres y animales.
\end{abstract}

Palabras clave: Baldo, Esopo, Esopete ystoriado, fábulas, versiones, libros de caballerías, didactismo, consejos, argumentación

\begin{abstract}
The author of Baldus presents us with a chivalric book in which the aim of entertainment is not of less importance than that of showing erudition and offering models for appropriate behavior in society. In order to get this objective the author combines the typical adventures from chivalric books with a myriad of references to classical authors among whom we find Aesop, whose fables had been compiled in the Esopete ystoriado. The present study offers a comparison of the Aesopian fables that are mentioned in Baldus with those appearing in the original text. We offer an analysis of the versions, their interpretation and the use the author of Baldus makes of them in his work: persuasion, advising about appropriate behavior, and pointing out the similarities between animal and human behavior.
\end{abstract}

Key words: Baldus, Aesop, Esopete ystoriado, fables, versions, chivalric books, didactic, advice, persuasion

\section{INTRODUCCIÓN}

La presencia de contenido didáctico en las obras del XVI era elemento necesario para que no fueran objeto de crítica por parte de los moralistas áureos. Aunque el valor didáctico de la lectura de hechos heroicos, verdaderos o no, ya había sido señalado en

${ }^{1}$ Correo-e: tomasap@hotmail.com. Recibido: 15-12-2012; segunda versión 26-02-2013. Aceptado: 15-032013. 
Las siete Partidas de Alfonso X y por otros autores como Feliciano de Silva o el propio autor del Baldo "¿Quién es de tan pequeña capacidad que luego no vea el provecho que le pueden dar las fábulas no perjudiciales?"2, esto no era óbice para que los críticos "estos severos Catones que quieren enviar las obras buenas, aunque fabulosas, a los infiernos con quien las hicieron" ${ }^{3}$ atacaran los libros de caballerías como lectura inútil . $^{4}$ Por eso se convierte casi en lugar común la alusión en los prólogos al carácter didáctico de estas obras a modo exculpatorio, en Baldo el autor dice que introduce enseñanzas de "filósofos morales para que tome algún provecho el lector a lo que va mi intención encaminada" 5 .

Martín Romero comenta que el entretenimiento en los libros de caballerías se ve "motivado por razones éticas, camuflado por ellas o, simplemente, mezclado con disquisiciones morales" ${ }^{\prime}$. Así, encontramos en el Baldo digresiones que recuerdan al sermón, aventuras caballerescas que sirven de modelo de comportamiento, pasando por citas de escritores antiguos y referencias cristianas. El presente trabajo introduce un elemento más a esta lista, la fábula esópica, cuya presencia está todavía sin estudio en los libros de caballerías. Se analiza ahora la presencia y el uso de tales textos en el Baldo con la intención de contribuir a abrir el camino a estudios similares en otros libros de caballerías.

\section{PRESENTACIÓN DE BALDO}

El Baldo, del que solo consta una edición fechada en 1542 en el taller de Domenico de Robertis, es el cuarto libro del ciclo Reinaldos de Montalbán. Esta obra tiene varias particularidades que la hacen distanciarse de los libros de caballerías al uso, en primer lugar y hasta el capítulo xxxv del primer libro se trata de una traducción de una obra italiana de 1521 del monje benedictino Teófilo Folengo que usa por seudónimo el nombre de Merlín Cocayo; por otro lado, no responde al patrón típico de los libros de caballerías pues en ella hay cabida para textos diversos que nos hacen recordar otros géneros que van desde el típicamente caballeresco a relatos que parecen anunciar la novela picaresca, pasando por reflexiones del autor y compilaciones de saber que recuerdan a misceláneas donde las obras clásicas conviven con las del renacimiento italiano y con textos de un carisma más popular que entroncan con las recopilaciones de fábulas esópicas y espejos de príncipes. Todo ello es fruto, como dice Lacarra, del "nuevo impulso que la literatura sapiencial cobra durante el humanismo" (2009: 323).

Aunque en su momento un libro de caballerías era todo lo opuesto a cualquier obra de la que se pudiera extraer ninguna utilidad, en el Baldo la intención didáctica

\footnotetext{
2 Baldo, pág. 4.

${ }^{3}$ Baldo, pág. 4.

${ }^{4}$ Sobre este tema ver Martín Romero, “Buenas doctrinas y enxemplos”. Aspectos sapienciales y didácticos en los libros de caballerías.

${ }^{5}$ Baldo, pág. 10.

${ }^{6}$ Martín (2004-2005).
} 
queda patente en estos comentarios que el autor añade a algunos de los capítulos y en los temas que ocupan capítulos enteros en los que el lector puede pensar haber cambiado de obra.

\section{TÉRMINO “FÁBULA"}

Siguiendo la definición de San Isidoro, las fábulas se oponen a todo lo que es verídico o histórico son "cosas non fechas, mas fingidas"7; son res fictae "Fabulas son aquellas cosas que ni son hechas ni pueden ser hechas, porque serían hechas fuera de la naturaleza" 8 frente a las res gestae "Las historias son verdaderas y así hechas como se cuentan" 9 .

En La vida de Esopo leemos:

Hay diversas fábulas, porque algunas son dichas "esópicas", las cuales hizo y compuso el muy clarísimo Esopo y son donde las animalias irracionales que no tienen habla son introducidas y fingidas que hablan ${ }^{10}$.

Y con estos dos significados usa el término el autor del Baldo como una historia ficticia opuesta a algo verídico incluyendo aquí ficciones, narraciones mitológicas y las fábulas tal y como las entendemos hoy, como corroboran estas citas: "No penséis que lo que nos cuenta Cíngar son fábulas. Esto es lo que yo vi y puede creerse"11; "Semejante es aquesto a la fábulilla de Isopo que cuenta del ratón ciudadano y del campesino"12.

\section{PRESENCIA DE FÁBULAS EN EL BALDO}

Al analizar las fábulas en el Baldo me centro tan solo en las "fábulas esópicas", dejando a un lado las simples menciones a animales que nos remiten a fábulas y obviando también otras con un carácter más oriental que recuerdan a las usadas para educar a príncipes, tales como la fábula del aldeano y el odre que Cíngar presenta en el capítulo XLI del Libro II del Baldo.

Así pues, tendríamos dos fábulas esópicas en el prólogo del Baldo: la raposa y las moscas; el caballo y el ciervo, además de una que inventa el propio autor: la de Ceres, la golondrina y la anguila. En el Libro I Falqueto presenta la fábula de la cogujada y la mies; dentro de los capítulos, el autor hace referencias a dos fábulas más: el perro y el trozo de carne; el león y la mosca. Y es en las anotaciones tras los capítulos donde se encuentra el mayor número de ellas: los dos ratones; el buey y la rana; la zorra y las peras; el cuclillo, el ruiseñor y el asno. Es decir, un total de 9 fábulas esópicas en toda la obra.

\footnotetext{
${ }^{7}$ Esopete Ystoriado, pág. 1.

${ }^{8}$ Esopete Ystoriado, pág. 2.

${ }^{9}$ Esopete Ystoriado, pág. 3.

${ }^{10}$ Esopete Ystoriado, pág. 1.

${ }^{11}$ Baldo, pág. 116.

${ }^{12}$ Baldo, pág. 168.
} 


\section{USO DE LAS FÁBULAS}

Bizarri (2011: 60) nos indica que ya Romulus a fines del siglo VIII o comienzos del IX hablaba del uso de las fábulas como modelo de conducta: "quid homines observare debeant. Verum ut vitam hominum et mores ostenderet": sirven, pues, para ofrecer "una forma figurada de representar las conductas humanas". En La vida de Esopo también se incide en esto:

E assi aquel que quiere leer este libro dela color dela flor, esto es dela fabula, non deve curar,
mas antes de la doctrina en ella contenida et inserta para adquirir y alcanzar buenas costumbres
y virtudes y para evitar y guardarse de los malos usos, chupando y tomando asi en vianda del
ánima y del cuerpo. (1)
El prólogo al primer libro del Esopete coincide con esto y añade además su tono lúdico:

Porque ayude y aproveche a la vida humana, el presente libro es compuesto a la manera de fábulas de reír, porque las cosas provechosas y necesarias mejor y más dulcemente se toman pintadas y fulcidas con cosas provocantes a risa y placer. (...) E la brevedad de las fábulas trae carga honesta de costumbres, como la cáscara seca cubre muchas veces el buen meollo. (33)

El prólogo al Baldo tiene un título muy significativo: "Prólogo sobre la poesía de Merlino Cocayo poeta Mantuano que demuestra cómo se ha de sacar utilidad de las fábulas y la causa por que se inventaron"13. Entendiendo aquí por "fábula" res ficticia y no solo en el sentido de "fábula esópica" aunque el autor también defiende las fábulas esópicas propiamente dichas: "las cuales claro está que muy poco daño traen porque ya se nombran por cosas falsas y la cosa clara no engaña"14.

También en el Baldo se señalan los dos usos anteriores a las fábulas: "dar exemplo a los humanos"15 entendiendo que hay que interpretarlas pues son una suerte de parábolas con un significado profundo y ayudan a decidir cómo actuar; el otro uso sería el atraer el ánimo y despertar el interés de quien escucha, siendo por eso buenas herramientas para trasmitir enseñanzas. Dice el autor en el prólogo en un pasaje que merece la pena transcribirse:

Asimismo las pusieron en sus obras grandes varones y celebérrimos filósofos como Platón, Aristóteles, Plutarco y Plinio porque son ellas de tal manera que penetran los ánimos de los lectores y con ciertas semejantes valen para conmover los ánimos de los hombres y de tal manera, que el oír las luengas oraciones e historias ordenadas enhastían, aunque sean de cosas provechosas, si no se entremeten estas fábulas. Seanos testigo un orador de Atenas que, orando delante del pueblo ateniense, como lo viese poco atento, rogóles que tuviesen por bien de oír una fábula. Ellos entonces dícenle que la diga y aguzan las orejas para oírla. Entonces él dice así: - Ceres, vuestra diosa -porque era allí adorada-, con la golondrina y la anguila yendo caminando, allegaron a un río. La golondrina lo pasó volando y la anguila nadando.

Como acabó el orador de decir esto, callóse un poco. Todos entonces comiénzanle a preguntar qué había hecho Ceres. Él respondió:

- Enojóse con vosotros vuestra diosa, porque no queréis oír las cosas provechosas pero muy atentos oís las consejas. (5)

13 Baldo,pág. 3.

14 Baldo, pág, 5.

15 Baldo, pág. 3. 
En el Baldo las fábulas se utilizan con tres intenciones: ofrecer un modelo de conducta, hacer comparaciones entre el comportamiento humano y el animal, y servir de argumento para defender una idea. Estas dos últimas ya las señalaban Burrus y Goldberg ${ }^{16}$.

A continuación presento un análisis de estos usos haciendo hincapié en las fábulas y su significado comparándolas con el Esopete Ystoriado, obra de 1488, que puede considerarse la fuente fabulística más conocida en la época.

\subsection{Uso como argumentación}

La mayor presencia de fábulas la tenemos en la "moralidad", "adición del trasladador" o "exclamación" con que concluyen alguno de los capítulos. Estos textos son creación propia del traductor del Baldo, que acude al tópico del manuscrito encontrado que no sólo traduce sino que decide enriquecer "y sabiendo bien que esto es fábula, metí también fábulas e historias antiguas" ${ }^{17}$ y continúa:

De adonde tuve por bien hacer al fin de los capítulos que fuesen menester sus adiciones sacadas de filósofos morales para que tome algún provecho el lector a lo que va mi intención encaminada, no como aquellos libros que solamente alegran y aún eso con gracias deshonestas. (9-10)

Estos elementos añadidos son reflexiones eruditas, repletas de citas a autores clásicos, personajes mitológicos y en ocasiones menciones a fábulas. El tema de los mismos se relaciona, con mayor o menor desenvoltura, con lo tratado en el capítulo, son comentarios al comportamiento de los personajes que incluso se someten a interpretaciones alegóricas en una clara intención didáctica de inculcar un comportamiento moralmente aceptado por la sociedad ${ }^{18}$.

La aparición de fábulas esópicas en estas adiciones responde a las necesidades del proceso argumentativo del autor que, para defender sus ideas, utiliza el apoyo de obras de escritores antiguos y, con intención de continuar un hilo discursivo, introduce las fábulas de Esopo sin considerarlas argumentos inferiores a las palabras de escritores clásicos consagrados, de hecho nos dice "más autoridad y provecho trae un refrán de los experimentados que un dicho de sabios"19.

\footnotetext{
${ }^{16}$ Aesopic fables are short illustrative narratives that illuminate some aspect of human behavior. In their literary realizations they are compiled with promythia or epimythia, or they are incorporated into a larger narrative where they either advance the action, describe the attributes of a character, or act as persuasive tools in discourse. Burrus y Goldberg (1990: viii).

${ }^{17}$ Baldo, pág. 8.

${ }^{18}$ Martin Romero señala el estudio de Cacho Blecua sobre el Amadís al respecto. No solo las acciones de los caballeros sino las de los propios dioses mitológicos eran objeto de interpretación alegórica con finalidad moral. Gernert citando a Jean Seznec (Los dioses de la Antigüedad en la Edad Media y el Renacimiento, Madrid, 1952, p.91) dice "los Dioses del Renacimiento continuaban siendo con mucha frecuencia, figuras didácticas incluso instrumentos para la edificación de las almas". (Genert: 2004: 90).

${ }^{19}$ Baldo, pág. 19.
} 
Dos veces hace mención a Esopo al presentar una fábula: la de los dos ratones y la de la zorra y las peras; en las restantes ocasiones bien se las atribuye a Horacio: la rana y el buey, o no se hace mención a la autoría.

\subsection{Uso en las moralidades}

Se usan para apoyar argumentos las siguientes fábulas:

La fábula de los dos ratones, que figura con el número XX en el Libro I del Esopete. Dos son los significados de esta fábula: por un lado defiende la pobreza frente a la riqueza, por otro critica a quienes se acercan a los poderosos para tener más de lo que les corresponde según su estado.

El autor del Baldo defiende la primera de las ideas, critica las riquezas de por sí, incluso las que se obtienen por el propio trabajo ya que el problema es la envidia que generan, por ello el que renuncia a los bienes es feliz. El autor sigue con agilidad la línea argumentativa del capítulo que cerraba con la historia de Arión y advierte contra los males que acarrea la posesión de riqueza. Se alude sólo al título de la fábula pues supone que el lector es conocedor de la misma.

Semejante es aquesto a la fábulilla de Isopo que cuenta del ratón ciudadano y del campesino, así que sólo aquel estaba descansado el que hubiere desechado las riquezas y no le pese de habérselas quitado otro. (I, 45.168)

La fábula de la rana y el buey también se usa para argumentar. Es la fábula XX del Libro II del Esopete. Comienza "si algún pobre quiere igualarse con algún poderoso, el tal se destruye y perece" termina con "Y por esto se dice: "no te hinches y no reventarás"(II.54). En una interpretación alegórica del capítulo precedente la nave de Baldo se equipara a la nave del mundo que navega por la vida. Los vientos son los vicios y el autor se centra en la ambición y es entonces cuando introduce la fabula del buey y la rana. Se produce un cambio ligero en el argumento con respecto al original pues se dice que el buey había matado a varias ranas antes de que una de ellas se enfrentara a él "la rana (...) como hubiese preguntado a un hijuelo suyo, que venía huyendo del buey que con los pies había trillado a sus hermanos" (I, 21.54), así el deseo de la rana nacería de un sentimiento de venganza. En la versión del Esopete se dice que el buey pacía en un prado cuando a una rana le entraron ganas de ser como él, el antojo estaría causado por la envidia: "una rana, viendo pacer un buey en el prado, pensó entre sí que podía ser tan grande si aquella su piel y cuero arrugado pudiese hinchar" (II.54).

Pero más importante es el cambio de significado pues mientras el Esopete advierte del peligro de autodestrucción que corre el pequeño al querer igualarse con el grande, el Baldo advierte contra los hombres de bajo estado que cometen robos, homicidios, conjuraciones, etc. por codicia, pues el pequeño urde conjuraciones contra el poderoso para acabar con él. El humilde es culpabilizado desde el principio por su intención casi innata de hacer daño.

la sedienta ambición ...es un deseo tan grave de honras que a los hombres hincha; a cada uno da diversas imaginaciones: a unos que han de ser grandes príncipes, que han de haber grandes 
dignidades, grandes honras. A los cuales quiera Dios no acontezca lo que a la rana que cuenta el poeta Horacio: la cual, como hubiese preguntado a un hijuelo suyo, que venía huyendo del buey que con los pies había trillado a sus hermanos, si podría ser ella tan grande como aquella bestia. - No, -respondió él- aunque revientes.

De adonde viene que un hombrecillo de zevil y muy bajo estado, de vil linaje y de peores condiciones, levante conjuraciones, acometa homicidios, haga latrocinios, trabe cuestiones sino por la ambición. (I, 21. 54)

Otra fábula que se usa para apoyar una tesis es la de la raposa y las peras, que encontramos abriendo el Libro IV del Esopete, la fábula I: "la primera fábula de la raposa y de las uvas"(IV.75).

En el Baldo hay algún cambio superficial, pues las uvas se sustituyen por peras que la raposa pretende hacer caer dando golpes con la cola. No hay que dirimir cuál es la versión original pues ya Jones recuerda "We must remember that a folktale is the sum of its versions; the versions are not partial reflections or evolved examples of an original, ideal text" Burrus y Goldberg (2002: xvii). ${ }^{20}$

El repertorio proverbial del Esopete facilitado por Lacarra (2009:310) indica sobre esta fábula: "Prudencia es disimular que no se procura la cosa cuando no se puede alcanzar", coincidiendo con el uso que se da en el Baldo. El capítulo XVIII, sin atacar la filosofía, acusa a los que después de haber desperdiciado su vida en argumentos filosóficos inútiles sin aplicación práctica que beneficie a la república fingen no interesarse por otros temas que en realidad desearían aprender.

"De adonde viene que los que en esto han gastado toda su vida y se vuelven a aprender las
otras cosas, pero, como no las pueden aprender porque están ya duros, menosprécianlas. Como
le aconteció en aquel tiempo que Hisopo dio palabras a los animales a la zorra, la cual como
hambrienta viese un gran peral, lleno de mucha fruta, comienza a dar con su cola al pie del
árbol pensando poder hacer caer algún fruto, pero como nunca pudo ni que cayesen las peras
que quería, se va diciendo que no aborrecía a más manjar que a las peras. Con estas fábula se
reprenden los que arriba dijimos que sobre cosas de poco seso se matan y gastan lo mejor de su
edad". (I, 18. 61-62)

La última fábula que se usa con intención argumentativa es la del ruiseñor, el cuclillo y el asno. No se podría asegurar si se trata de la fábula IV del Libro IV del Esopete "de Juno y del pavón y del ruiseñor" pues solo comparte algunos elementos comunes: el canto del ruiseñor causa envidia a otros. En el Baldo el envidioso es el cuclillo, en el Esopete el pavo real; en ambas obras aparece la figura de un juez: en Baldo es un asno, en el Esopete, Juno; en el Esopete Juno dictamina que cada animal tiene su don propio, su talento mientras que en el Baldo el ruiseñor pierde frente al cuclillo concluyendo así que los torpes no aprecian la verdad o que no todo juez sabe juzgar o que no hay que fiarse de las apariencias pues las orejas grandes no implican necesariamente saber oír. La "moralidad" del capítulo es una reivindicación de la verdad. Se menciona esta fábula para ejemplificar cómo la verdad es menospreciada de los hombres porque no pueden entender su belleza.

\footnotetext{
${ }^{20}$ Burrus y Goldberg, pg. 182, (en Jones, Steven Swann “The structure of Snow White. In Fairy Tales and Society: Illusion, Allusion, and Paradigm. Ed. Ruth B. Bottigheimer.Philadelphia: University of Pennsylvania Press, 1986, 165-86)
} 


\begin{abstract}
Anda la verdad en este tiempo buscando hombres que la acojan, menospreciada de los malos como el ruiseñor, el cual una vez contendió a cantar con el cuclillo y escogieron al asno por juez porque tenía más luengas orejas y así pensaron que oiría mejor. Habiendo cantado el harpado ruiseñor y el ronco cuclillo delante de él, él dio la victoria al cuclillo condenando al dulce canto del ruiseñor porque no lo entendía. De adonde esta ave enojada apeló a los hombres, y, siempre cuando ve a alguno, se para a cantar más suavemente que cuando está solo para que juzgue por él. Pero el hombre entendiendo lo que es su intención, no pasa sin darle victoria. (I, 7. 31)
\end{abstract}

\title{
5.3 Uso como modelo de conducta
}

Como señalé al comienzo, otro de los usos de la fábula es el servir de modelo de conducta y en el prólogo al Baldo se ofrecen dos ejemplos que se aplican para el regimiento de reinos.

El autor del Baldo hace referencia a la fábula IX del Libro IV del Esopete "del caballo y del ciervo y del cazador" para aludir a un hecho histórico en el que el uso de una fábula evitó que un pueblo fuera sometido. Esta fábula mantiene el mismo significado que en el repertorio proverbial del Esopete: "No ponga el hombre enemistad con quien le pese después de haberla tomado."

el poeta Stesichoro apartó a los ciudadanos de Hímera con la fábula del caballo que, por vengarse del ciervo, se dejó enfrenar y, después de vencido, se quedó en poder del hombre a que, para vengarse, no tomasen al tirano Falaris, rey de los agrigentinos, porque aunque venciesen a sus enemigos, quedarían en sujeción perpetua. (7)

La segunda fábula esópica mencionada pero que no figura en el Esopete es la de la raposa y las moscas. ${ }^{21}$

Asimismo el fabulador Isopo aportó a los de Samo con la fábula de la raposa mordida de las moscas que no mudasen jueces. Por esta causa Tiberio César daba los magistrados de luengo tiempo, porque no perdona a los pueblos el reino breve. (7)

En La vida de Esopo el protagonista alecciona a los habitantes de Samo no con esta fábula sino con la de los lobos, las ovejas y los perros. Esto quizás indique que el autor del Baldo manejaba una versión distinta de La vida de Esopo.

Tenemos otra fábula, la más extensa del Baldo, que no aparece recogida en el Esopete sino en Noctes atticae de Aulo Gelio y que sin embargo este autor la atribuye a Esopo. Gernert sugiere como título para ella "la cogujada y la mies" 22. Esta fábula ocupa todo el capítulo XXIX del libro II de Las noches áticas: "A pologus Aesopi Phrygis memoratu non inutilis" Apólogo útil de Esopo el Frigio. Se presenta la fábula tras dedicar a Esopo un reconocimiento:

enseñó no con la imperiosa severidad de un filósofo que dogmatiza, sino disimulando sus lecciones bajo fábulas picantes y amables que hacen entrar las más útiles reflexiones en la mente conquistada por la atracción de lo ameno (vol.I, 173).

\footnotetext{
${ }^{21}$ El fabulador francés La Fontaine introduce en el Libro XII de sus Fábulas una semejante que lleva el número 13: El zorro, la mosca y el erizo (1940: 240).

${ }^{22}$ Baldo, pág. Xiii.
} 
Nuestro autor siguió en el Baldo el mismo espíritu que movía a Aulio Gelio en su obra: compilar enseñanzas interesantes para que el público de su libro tuviera una honesta erudición. Si analizamos el texto original vemos que el autor del Baldo hace casi una traducción literal del mismo aunque suprime algún comentario: el hecho de que los polluelos estas aves cuando llega la siega ya tienen plumas; y añade algún otro: se dice que la cogujada es "vieja y experimentada".

Falqueto, haciendo de narrador metadiegético, es quien nos cuenta esta fábula que oyó de boca de un pastor anciano y que empieza con un proverbio: "no confíes en otros sino en ti" (I, 7. 28-29). El pastor, que con su hijo espera infructuosamente ayuda de parte de vecinos y familiares para esquilar el rebaño, recuerda por la similitud del escenario la fábula de la cogujada, en la que se cambia el esquilar ovejas por recoger el trigo. Seguidamente el padre recalca al hijo también la lección: “Esto nos amonesta, hijo, que no confiemos como livianos en el socorro de nuestros amigos o parientes" (I, 7. 29). Por la excesiva extensión de la misma y las limitaciones de espacio no se reproduce.

\subsection{Uso como comparación.}

Es lugar común decir que el reino animal nos ofrece comportamientos que pueden compararse con los de los hombres, y de hecho las fábulas utilizan esto como rasgo distintivo de género. Así, La vida de Esopo comienza explicando su origen: "fueron falladas porque por las palabras fingidas delas animalias irracionales de unas a otras la imagen \& costumbres de los ombres fuesen conoscidas" ${ }^{23}$.

En el propio Baldo se dice que las transformaciones o metamorfosis en piedras, árboles, aves o animales que sufren quienes se pasean por el infierno responden a las características de las personas.

Circe, convertidora de hombres en brutos animales, enseña los hombres solamente en la forma y humana voz ser presto convertidos en los torpes deseos a que su voluntad y inclinación atrae no les contradiciendo semejándose cada uno a la forma que ama: como los libidinosos en osos, los soñolientes en puercos, los tragones en lobos, los feroces sin saber en leones y así los otros. (6)

La primera aparición de una fábula que compara el comportamiento de unos hombres al comportamiento que se refleja en una fábula la tenemos en el capítulo XVII. Siguiendo el estilo heterodoxo propio del Baldo, en el capítulo XVII el hecho de llegar a una playa con piedras que brillan y descubrir entre ellas la piedra filosofal da lugar para relatar a Cíngar la historia del vidrio. El capítulo parece transformarse en un ensayo sobre la alquimia que se prolonga hasta el capítulo siguiente y que tiene por protagonistas no ya a los caballeros sino a los filósofos y nigrománticos de Corintio a quienes los ciudadanos movidos por la avaricia requerían para que les enseñaran el arte de la alquimia llegando a vender sus posesiones para conseguirlo. Es entonces cuando el autor, a modo de comparación y no como argumentación en favor de ninguna idea, menciona la fábula del "perro y el trozo de carne" con el mismo significado que en la

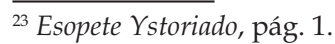


fábula V del Libro I del Esopete: "no debe el hombre, codiciando lo ajeno y dudoso, dejar lo suyo que es cierto, aunque lo que codicia le parezca más" (I.34).

Todos los más vendían sus haciendas, dándoselas a los filósofos porque las multiplicasen, pensando quedar muy ricos. No parecía sino al perro que dejaba el bocado que tenía por la mayor sombra que en el agua veía y perdiólo todo. (I, 18.59)

Tenemos otro momento en que el autor del Baldo menciona una fábula para hablar del comportamiento de dos caballeros, la del león y la mosca.

No mirando esto Beliarte de él, dándole recios golpes como la pequeña mosca que al grande león pica, confiándose en el vuelo y el león se va poco a poco ensañando, así Baldo se iba airando y, por derribarlo, le dio un pequeño golpe en los pechos, mas, dando la punta de la espada en cosa blanda, que era un jubón, se entró por los pechos atravesándole el corazón. (II, 32. 232)

Podemos rastrear en el Libro II del Ysopete la fábula XII con un significado similar, si bien con otros personajes, el calvo y la mosca (II. 52). La intención didáctica coincidiría pues nos enseña que no debemos hacer mal a otros que sin ningún trabajo pudieran causarnos desgracia, el calvo aunque se haga daño con sus propios manotazos mata la mosca. Esta mención a la fábula nos vuelve a indicar que nuestro autor tal vez no manejara la misma edición del Ysopete, o que introducía variantes conocidas en la época.

\section{CONCLUSIÓN}

El Baldo es un libro de caballerías poco ortodoxo en cuanto al rigor temático propio de estas obras pues da cabida a un amplio repertorio textual. La avalancha de material erudito se distribuye de forma muy desigual en una trabazón vertiginosa de referencias a fabulas, citas clásicas y doctrina religiosa, donde lo culto y lo popular se encuentran.

En este modo de narrar distinto, las fábulas, elemento propio de la literatura popular, se colocan al lado de menciones a Aristóteles, Platón, Ovidio, Sócrates, etc. adquiriendo así la misma categoría y se usan a discreción cuando el autor necesita apoyar sus ideas, proponer semejanzas entre el comportamiento humano y animal, o dar consejos. Estas enseñanzas fabuladas no podían dejarse de lado en una época en que la literatura didáctica está en pleno auge. El autor recoge la tradición clásica de las fábulas aunque adaptándolas a sus intenciones narrativas incorporando nuevas interpretaciones y usando versiones distintas de las más conocidas.

El autor del Baldo sin duda acallaría cualquier comentario que atacara su obra por carencia de utilidad pues de manera efectiva cumple lo que promete en su prólogo "que tome algún provecho el lector"(10). El autor confecciona un texto complejo y denso lleno de enseñanzas propias de una obra de misceláneas, un compendio del saber del momento que sirve de base para proponer modelos de conducta útiles para vivir en sociedad, y en el que las fábulas esópicas encuentran un espacio al lado de las obras clásicas ya consagradas. 


\section{BIBLIOGRAFÍA}

Bizarri, H. (2011): “El Esopete ystoriado y las teorías sobre la fábula", Acta Poética, 322:55-73

Burrus, V. y Goldberg, H. (eds.) (1990): Esopete Ystoriado (Toulouse, 1488), Madison, Hispanic Seminary of Medieval Studies.

Cattan, F. “Adaptaciones ciceronianas en Noctes Atticae de Aulo Gelio", en V Jornadas de estudios clásicos y medievales "diálogos culturales". Universidad Nacional de la Plata, Argentina.

Gelio, A. (2006), Noctes Atticae, Marcos Casquero, M.A. y Domínguez García, A. (eds.), 2 vol. , León, Universidad de León.

Gernert, F. (2004): “La recepción de la mitología en los libros de caballerías: El Baldo (1542)", en Friedlein, R. y Neumeister, S. (eds.) (2004): La mitología antiga a les literatures catalana $i$ castellana entre l'Edat Mitjanai la Moderna, Barcelona, Publicacions de 1'Abadia de Montserrat, 85-93.

Gernert, F. (ed.) (2002), Baldo (Sevilla, 1542), Alcalá de Henares, Centro de Estudios Cervantinos.

Gernert, F, (2000): Baldo. Guía de lectura, Alcalá de Henares, Centro de Estudios Cervantinos.

Lacarra, M.J., (2009) "Fábulas y proverbios en el Esopo Anotado", Revista de poética medieval, 23: 297-329.

La Fontaine (1940), Fabulas, Barcelona, Montaner y Simon.

Martín Romero, J. J. "Buenas doctrinas y enxemplos". Aspectos sapienciales y didácticos en los libros de caballerías, Memorabilia 8 (2004-2005) [parnaseo.uv.es/ memorabilia/memorabilia8/martin/index.htm] (consultado en octubre de 2012) 